Drożak Paulina, Bryliński Lukasz, Bura Agata, Duda Piotr, Augustowska Katarzyna, Mizerski Grzegorz. Determining environmental predictors of subjective feeling of depressive symptoms among Polish medical students. Journal of Education, Health and Sport. 2020;10(5):133-148. eISSN 2391-8306. DOI http://dx.doi.org/10.12775/JEHS.2020.10.05.014

https://apcz.umk.pl/czasopisma/index.php/JEHS/article/view/JEHS.2020.10.05.014

https://zenodo.org/record/3837614

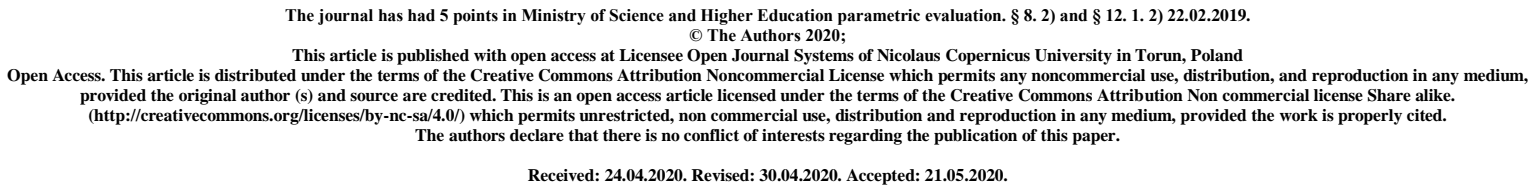

\title{
Determining environmental predictors of subjective feeling of depressive symptoms among Polish medical students
}

\author{
Paulina Drożak $^{1}$, Lukasz Bryliński ${ }^{1}$, Agata Bura ${ }^{1}$, Piotr Duda $^{1}$, Katarzyna Augustowska ${ }^{1}$, \\ Grzegorz Mizerski ${ }^{1}$
}

1. Chair and Department of Family Medicine, Medical University of Lublin.

\begin{abstract}
Introduction and objective. Depression is a disease that impairs daily functioning. According to research, as much as $27.2 \%$ of medical students suffer from depression or show depressive symptoms and $11.1 \%$ of them experience suicidal ideation. The aim of the research was to investigate the occurrence of subjective feeling of depressive symptoms among Polish medical students during the course of their medical studies and to determine predictors of this phenomenon that are related to student's environment.

Material and method. A total of 1023 medical students from each year of medical education and different Polish universities took part in the study. The research tool was an author's questionnaire. Obtained data was subjected to a statistical analysis. To assess the relationship between two variables, the chi-square test of independence was used. The level of significance was set at $\mathrm{p}<0.05$.

Results. The statistical analysis showed that most respondents (52.79\%) had noticed symptoms that might had pointed to depression during their medical studies. A statistically significant link was found between subjective feeling of depressive symptoms during the course of medical studies and: mother's level of education, relationship with parents, relationship with siblings, relationship with friends, knowing a person that one could count on in a difficult situation, knowing a person in which one could trust with all their problems,
\end{abstract}


frequent feelings of loneliness and feeling that one doesn't participate in social gatherings often enough.

Conclusions. The prevalence of subjective feeling of depressive symptoms among medical students is high. Results suggest that good relationships with others are important in prevention of depression.

Key words: depression; medical students

\section{Introduction}

According to World Health Organization, depression is a disease characterized by: sadness, loss of interests and ability of feeling pleasure, feeling of guilt, low self-esteem, sleep and appetite disturbances, feeling of fatigue and impairment of concentration. It is also associated with reduced functioning capacity in all aspects of life, including the professional one. One of the groups particularly subjected to depression are medical students. According to analysis based on research conducted in 43 countries among medical students, $27.2 \%$ of them suffer from depression or show depressive symptoms and $11.1 \%$ of them experience suicidal ideation [1]. Many reasons exists behind high prevalence of depression in the abovementioned group, including: workload, pressure (of time, but also environmental one), personality type and character traits of a student, such as: conscientiousness, individual approach to studies or ability to handle stress [2,3,4,5,6]. Interestingly, religious individuals, those with poor physical health, those with mental health disturbances (in themselves or in a member of family), low economic status or bad relationship with their parents are more susceptible to depression [7,8,9]. Depression is not only a threatening illness that impairs functioning, but also results in detrimental consequences, such as worse academic achievements and resignation from university [10,11]. According to research, among those who decide to temporarily or completely quit from medical studies, condition of mental health was second (after difficulties with learning) most common cause of withdrawal from education [12]. Graduation doesn't resolve the problem, because depression among doctors is also a disturbing issue. Specialists who suffer from this disease are at six time higher risk of committing a medical error [13].

\section{Objective}

The aim of the research was to investigate the occurrence of subjective feeling of depressive symptoms among Polish medical students and to determine predictors of this phenomenon that are related to student's environment.

\section{Material and method}

A total of 1023 medical students (773 females and 250 males) took part in the study. Among respondents there were students enrolled in each of the 18 universities in Poland that offer medical education. Students of each year of medical education took part in the study: $34.41 \%$ $(\mathrm{n}=352)$ respondents studied in the 1st year, $25.51 \%(\mathrm{n}=261)-$ in the 2 nd year, $18.77 \%(\mathrm{n}=$ $192)$ - in the 3rd year, $10.36 \%(n=106)$ - in the 4th year, 7.04\% $(n=72)-$ in the 5 th year and $3.91 \%(n=40)$ - in the 6 th year. Mean age of participants was 21.55 years. Author's 
questionnaire containing closed one-choice questions with Likert scale was used. Questions concerned the sociodemographic characteristics of the investigated group and analyzed factors. Answers were collected in April of 2020 through placing the research tool on groups dedicated to different classes of medical students of different Polish universities on Facebook social networking service. The questionnaire was anonymous, and participation in the research was voluntary. Obtained data was subjected to a statistical analysis. To assess the relationship between two variables, the chi-square test of independence was used. The level of significance was set at $\mathrm{p}<0.05$.

\section{Results}

Results indicate that to the question „During your medical studies, have you ever noticed symptoms in yourself that might had pointed to depression?" a little over majority of participants $(52.79 \% ; \mathrm{n}=540)$ answered positively: $26.98 \%(\mathrm{n}=276)$ definitely yes and $25.81 \%(n=264)$ rather yes. $19.16 \%(n=196)$ of respondents indicated their answer to this question as hard to tell. Whereas $28.05 \%(\mathrm{n}=287)$ of respondents answered negatively: $19.55 \%(\mathrm{n}=200)$ - rather not and 8.50\% $(\mathrm{n}=87)$ - definitely not. Among participants who had noticed symptoms that might had pointed to depression during the course of their medical studies, $41.00 \%(\mathrm{n}=221)$ sought professional help and $66.01 \%(\mathrm{n}=371)$ turned to a trusted person with this problem.

$13.49 \%(n=138)$ of the respondents had diagnosed depression, of which $68,12 \%(n=94)$ had been diagnosed with this disease during the course of their medical studies and $31,88 \%$ ( $\mathrm{n}=$ 44) - before entering medical studies.

During medical studies, women more often $(54.98 \%)$ than men $(46.00 \%)$ had noticed symptoms that might had pointed to depression. The established differences were close to statistical significance $\left(\mathrm{Chi}^{2}=8.92 ; \mathrm{p}=0.06\right)$.

Women more often $(41.88 \%)$ than men $(37.72 \%)$ sought professional help in case of noticing in themselves symptoms that might had pointed to depression. The established differences weren't statistically significant $\left(\mathrm{Chi}^{2}=2.58 ; \mathrm{p}=0.28\right)$. Similarly, a little higher percentage of women $(69.02 \%)$ than men $(55.28 \%)$ turned with this problem to a trusted person. The established differences were statistically significant $\left(\mathrm{Chi}^{2}=8.08 ; \mathrm{p}=0.004\right)$.

The research didn't show a link between noticing symptoms that might had suggested depression during studying medicine and size of hometown. This percentage was similar in all cases and equaled: $51.71 \%$ - among respondents who were residents of the countryside, $51.74 \%$ - among respondents who lived in small towns (population up to 50000 inhabitants), $57.29 \%$ - among respondents who lived in medium cities (population from 50000 to 200000 inhabitants) and 51.99\% - among respondents who lived in big cities (population more than 200000 inhabitants). However, the bigger the hometown, the higher percentage of participants who had noticed symptoms, sought professional help. This percentage equaled: $34.67 \%$ among inhabitants of villages, $40.30 \%$ - among inhabitants of small towns, $42.73 \%$ among inhabitants of medium cities and $46.90 \%$ - among inhabitants of big cities. The established differences weren't statistically significant $\left(\mathrm{Chi}^{2}=4.73 ; \mathrm{p}=0.19\right)$.

Among respondents who lived in their family homes while studying, $49.67 \%$ had noticed symptoms that might had pointed to depression during the course of their medical studies. Whereas among those who lived outside of their family homes when studying this percentage 
was slightly higher $(53.55 \%)$. The established differences weren't statistically significant $\left(\mathrm{Chi}^{2}=1.68 ; \mathrm{p}=0.80\right)$.

The research shows that the symptoms that might had pointed to depression where most often recognized during medical studies by individuals whose mother had primary, lower secondary or upper secondary education $(57.56 \%)$. Whereas such symptoms were noticed the least often among those whose mother had basic vocational education (42.53\%). Among respondents whose mother had higher education, this percentage had a medium value $(52.62 \%)$. The established differences were statistically significant $\left(\mathrm{Chi}^{2}=23.05 ; \mathrm{p}=0.003\right)$. [Table 1.]

Table 1. Link between noticing symptoms that might had pointed to depression during the course of medical studies and mother's level of education.

\begin{tabular}{|c|c|c|c|c|c|c|c|c|}
\hline \multirow{3}{*}{\multicolumn{2}{|c|}{$\begin{array}{l}\text { Statistical analysis: } \\
\begin{array}{c}\mathrm{Chi}^{2}=\mathbf{2 3 . 0 5} \\
\text { df }=\mathbf{8} \\
\text { p }=\mathbf{0 . 0 0 3}\end{array}\end{array}$}} & \multicolumn{7}{|c|}{ Mother's level of education } \\
\hline & & \multicolumn{2}{|c|}{$\begin{array}{c}\text { Primary or } \\
\text { lower secondary } \\
\text { or upper } \\
\text { secondary }\end{array}$} & \multicolumn{2}{|c|}{ Basic vocational } & \multicolumn{2}{|c|}{ Higher } & \multirow{2}{*}{$\begin{array}{c}\text { Tota } \\
\mathrm{n}\end{array}$} \\
\hline & & $\mathrm{n}$ & $\%$ & $\mathrm{n}$ & $\%$ & $\mathrm{n}$ & $\%$ & \\
\hline \multirow{4}{*}{$\begin{array}{c}\text { During the } \\
\text { course of your } \\
\text { medical } \\
\text { studies, have } \\
\text { you ever } \\
\text { noticed } \\
\text { symptoms in } \\
\text { yourself that } \\
\text { might had } \\
\text { pointed to } \\
\text { depression? }\end{array}$} & $\begin{array}{l}\text { Definitely yes } \\
\text { or Rather yes }\end{array}$ & 99 & $57.56 \%$ & 37 & $42.53 \%$ & 402 & $52.62 \%$ & 538 \\
\hline & Hard to tell & 42 & $24.42 \%$ & 24 & $27.59 \%$ & 134 & $17.54 \%$ & 200 \\
\hline & $\begin{array}{l}\text { Rather not or } \\
\text { Definitely not }\end{array}$ & 31 & $18.02 \%$ & 26 & $29.89 \%$ & 228 & $29.84 \%$ & 285 \\
\hline & Total & 172 & $100.00 \%$ & 87 & $100.00 \%$ & 764 & $100.00 \%$ & 1023 \\
\hline
\end{tabular}

Taking into account father's education, the highest percentage of respondents who had noticed symptoms that might had pointed to depression during the course of medical studies, was noticed among those whose father had higher education (54.01\%). Whereas such symptoms were the least often recognized among respondents whose father had basic vocational education (49.54\%). Among participants whose father had basic, lower secondary or upper secondary education, this percentage had a medium value $(52.62 \%)$. The established differences weren't statistically significant $\left(\mathrm{Chi}^{2}=6.61 ; \mathrm{p}=0.16\right)$.

According to obtained results, the highest percentage $(55.13 \%)$ of respondents who had noticed symptoms that might had pointed to depression during medical studies was noticed among respondents whose mother was a doctor of medicine or dental medicine. Whereas this 
percentage equaled $53.14 \%$ among participants who didn't have a doctor parent, $51.43 \%$ among those whose both parents were medical doctors and $46.77 \%$ - among those, whose father was a medical doctor. The established differences weren't statistically significant (Chi ${ }^{2}$ $=2.73 ; \mathrm{p}=0.84$ ).

The results showed a highly statistically significant link between relationship with mother or not having a mother and subjective feeling of symptoms that might had pointed to depression during the course of medical studies $\left(\mathrm{Chi}^{2}=32.51 ; \mathrm{p}=0.0000015\right)$. Among respondents who defined their relationship with mother as very good or good, the percentage of those who had noticed symptoms that might had pointed to depression was the lowest (48.47\%). Whereas this percentage equaled $63.75 \%$ among those who defined their relationship with mother as average and $80.00 \%$ among those who defined this relationship as bad or very bad or those who didn't have a mother. Similarly, a highly statistically significant link was noticed between a relationship with father or not having a father and subjective feeling of symptoms that might had pointed to depression during the course of medical studies $\left(\mathrm{Chi}^{2}=43.40 ; \mathrm{p}=\right.$ $\left.8.18 \times 10^{-9}\right)$. Among respondents who defined their relationship with father as very good or good, the percentage of those who had noticed symptoms that might had pointed to depression was the lowest $(43.97 \%)$. Whereas this percentage equaled $63.45 \%$ among those who defined this relationship as average and $65.46 \%$ among those who defined their relationship with father as bad or very bad or didn't have a father. [Table 2.] 
Table 2. Link between noticing symptoms that might had pointed to depression during the course of medical studies and relationship with parents.

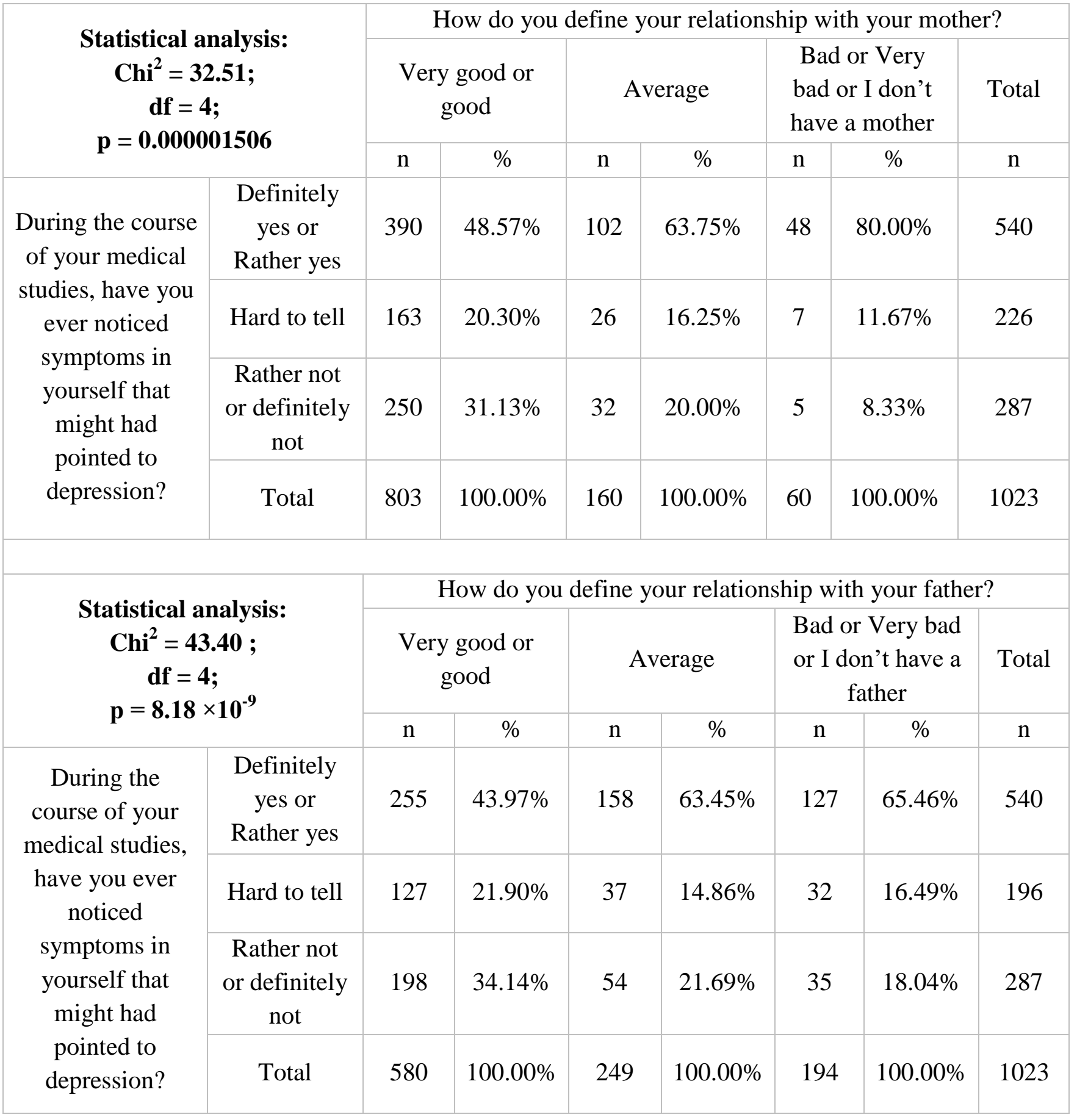

Results of the research concerning a group of participants that had siblings, showed that respondents who defined their relationship with siblings as very good or good, the least often (50.00\%) had noticed symptoms that might had pointed to depression during the course of their medical studies. In case of respondents who claimed this relationship as average, this percentage had a medium value $(61.90 \%)$. The highest value $(73.33 \%)$ was observed among participants who defined their relationship with siblings as bad or very bad. The established differences were statistically significant $\left(\mathrm{Chi}^{2}=17.55 ; \mathrm{p}=0.0015\right)$. [Table 3.] 
Table 3. Link between noticing symptoms that might had pointed to depression during the course of medical studies and relationship with siblings.

\begin{tabular}{|c|c|c|c|c|c|c|c|c|}
\hline \multirow{3}{*}{\multicolumn{2}{|c|}{$\begin{array}{l}\text { Statistical analysis: } \\
\begin{array}{c}\mathrm{Chi}^{2}=17.55 \\
\text { df }=4 \\
\text { p }=0.0015\end{array}\end{array}$}} & \multicolumn{7}{|c|}{ How do you define your relationship with your siblings? } \\
\hline & & \multicolumn{2}{|c|}{$\begin{array}{l}\text { Very good or } \\
\text { good }\end{array}$} & \multicolumn{2}{|c|}{ Average } & \multicolumn{2}{|c|}{$\begin{array}{l}\text { Bad or Very bad } \\
\text { or I don't have a } \\
\text { father }\end{array}$} & \multirow{2}{*}{$\begin{array}{c}\text { Total } \\
\text { n }\end{array}$} \\
\hline & & $\mathrm{n}$ & $\%$ & $\mathrm{n}$ & $\%$ & $\mathrm{n}$ & $\%$ & \\
\hline \multirow{4}{*}{$\begin{array}{l}\text { During the course } \\
\text { of your medical } \\
\text { studies, have you } \\
\text { ever noticed } \\
\text { symptoms in } \\
\text { yourself that might } \\
\text { had pointed to } \\
\text { depression? }\end{array}$} & $\begin{array}{c}\text { Definitely yes } \\
\text { or Rather yes }\end{array}$ & 316 & $50.00 \%$ & 104 & $61.90 \%$ & 33 & $73.33 \%$ & 453 \\
\hline & Hard to tell & 117 & $18.51 \%$ & 31 & $18.45 \%$ & 5 & $11.11 \%$ & 153 \\
\hline & $\begin{array}{l}\text { Rather not or } \\
\text { definitely not }\end{array}$ & 199 & $31.49 \%$ & 33 & $19.64 \%$ & 7 & $15.56 \%$ & 239 \\
\hline & Total & 632 & $100.00 \%$ & 168 & $100.00 \%$ & 45 & $100.00 \%$ & 845 \\
\hline
\end{tabular}

The analysis showed a highly statistically significant link between relationship with friends or not having any friends and noticing symptoms that might had pointed to depression during the course of medical studies. Respondents, who defined their relationship with friends as very good or good, had noticed symptoms that might have pointed to depression during the course of their medical studies the least often (47.71\%). Among those, who described this relationship as average, such percentage equaled $64.50 \%$. Whereas the highest value (76.00\%) was noticed among those who defined their relationship with friends as bad or very bad or didn't have any friends. The established differences were statistically significant (Chi ${ }^{2}$ $\left.=39.25 ; \mathrm{p}=6.2 \times 10^{-8}\right)$. [Table 4.] 
Table 4. Link between noticing symptoms that might had pointed to depression during the course of medical studies and relationship with friends.

\begin{tabular}{|c|c|c|c|c|c|c|c|c|}
\hline \multirow{3}{*}{\multicolumn{2}{|c|}{$\begin{array}{l}\text { Statistical analysis: } \\
\qquad \begin{array}{c}C h i^{2}=39.25 \\
\text { df }=4 \\
p=6.20 \times 10^{-8}\end{array}\end{array}$}} & \multicolumn{7}{|c|}{ How do you define your relationship with your friends? } \\
\hline & & \multicolumn{2}{|c|}{$\begin{array}{l}\text { Very good or } \\
\text { good }\end{array}$} & \multicolumn{2}{|c|}{ Average } & \multicolumn{2}{|c|}{$\begin{array}{l}\text { Bad or Very bad } \\
\text { or I don't have } \\
\text { any friends }\end{array}$} & \multirow{2}{*}{$\begin{array}{c}\text { Total } \\
\mathrm{n}\end{array}$} \\
\hline & & $\mathrm{n}$ & $\%$ & $\mathrm{n}$ & $\%$ & $\mathrm{n}$ & $\%$ & \\
\hline \multirow{4}{*}{$\begin{array}{l}\text { During the } \\
\text { course of your } \\
\text { medical } \\
\text { studies, have } \\
\text { you ever } \\
\text { noticed } \\
\text { symptoms in } \\
\text { yourself that } \\
\text { might had } \\
\text { pointed to } \\
\text { depression? }\end{array}$} & $\begin{array}{l}\text { Definitely yes } \\
\text { or Rather yes }\end{array}$ & 365 & $47.71 \%$ & 129 & $64.50 \%$ & 38 & $76.00 \%$ & 532 \\
\hline & Hard to tell & 148 & $19.35 \%$ & 41 & $20.50 \%$ & 7 & $14.00 \%$ & 196 \\
\hline & $\begin{array}{l}\text { Rather not or } \\
\text { definitely not }\end{array}$ & 252 & $32.94 \%$ & 30 & $15.00 \%$ & 5 & $10.00 \%$ & 287 \\
\hline & Total & 765 & $100.00 \%$ & 200 & $100.00 \%$ & 50 & $100.00 \%$ & 1023 \\
\hline
\end{tabular}

The research shows that the lowest percentage (48.85\%) of those who had noticed symptoms that might had pointed to depression during the course of medical studies was found among respondents who knew a person they could count on in a difficult situation. Among respondents who declared their answer as hard to tell whether they knew such person, the percentage had a medium value $(74.26 \%)$. Whereas among those who claimed that they didn't have such person in their environment, this percentage had the highest value $(76.92 \%)$. The established differences were statistically significant $\left(\mathrm{Chi}^{2}=42.03 ; \mathrm{p}=1.569 \times 10^{-8}\right)$. Similarly, the analysis showed that respondents who knew a person in whom they could trust with all their problems, the least often had noticed signs that might had pointed to depression during the course of their medical studies (49.43\%). Among those who claimed their answer as hard to tell whether they knew such person, this percentage had a medium value $(60.18 \%)$. Whereas among respondents who didn't know such person, this percentage had the highest value $(67.20 \%)$. The established differences were statistically significant $\left(\mathrm{Chi}^{2}=19.39 ; \mathrm{p}=\right.$ 0.0007). [Table 5.] 
Table 5. Link between noticing symptoms that might had pointed to depression during the course of medical studies and knowing a person that one could count on in a difficult situation and knowing a person that one can trust with all their problems.

\begin{tabular}{|c|c|c|c|c|c|c|c|c|}
\hline \multirow{3}{*}{\multicolumn{2}{|c|}{$\begin{array}{l}\text { Statistical analysis: } \\
\qquad \begin{array}{c}\mathrm{Chi}^{2}=42.03 ; \\
\text { df }=4 ; \\
p=1.57 \times 10^{-8}\end{array}\end{array}$}} & \multicolumn{7}{|c|}{$\begin{array}{l}\text { Do you know a person that you can count on in a difficult } \\
\text { situation? }\end{array}$} \\
\hline & & \multicolumn{2}{|c|}{$\begin{array}{l}\text { Definitely yes or } \\
\text { Rather yes }\end{array}$} & \multicolumn{2}{|c|}{ Hard to tell } & \multicolumn{2}{|c|}{$\begin{array}{l}\text { Rather not or } \\
\text { definitely not }\end{array}$} & \multirow{2}{*}{$\begin{array}{c}\text { Total } \\
\mathrm{n}\end{array}$} \\
\hline & & $\mathrm{n}$ & $\%$ & $\mathrm{n}$ & $\%$ & $n$ & $\%$ & \\
\hline \multirow{4}{*}{$\begin{array}{c}\text { During the } \\
\text { course of your } \\
\text { medical studies, } \\
\text { have you ever } \\
\text { noticed } \\
\text { symptoms in } \\
\text { yourself that } \\
\text { might had } \\
\text { pointed to } \\
\text { depression? }\end{array}$} & $\begin{array}{l}\text { Definitely yes } \\
\text { or Rather yes }\end{array}$ & 425 & $48.85 \%$ & 75 & $74.26 \%$ & 40 & $76.92 \%$ & 540 \\
\hline & Hard to tell & 172 & $19.77 \%$ & 18 & $17.82 \%$ & 6 & $11.54 \%$ & 196 \\
\hline & $\begin{array}{l}\text { Rather not or } \\
\text { definitely not }\end{array}$ & 273 & $31.38 \%$ & 8 & $7.92 \%$ & 6 & $11.54 \%$ & 287 \\
\hline & Total & 870 & $100.00 \%$ & 101 & $100.00 \%$ & 52 & $100.00 \%$ & 1023 \\
\hline \multirow{3}{*}{\multicolumn{2}{|c|}{$\begin{array}{l}\text { Statistical analysis: } \\
\qquad \begin{array}{c}\mathrm{Chi}^{2}=19.39 ; \\
\text { df }=4 ; \\
p=0.0007\end{array}\end{array}$}} & \multicolumn{7}{|c|}{ Do you know a person that you can trust with all your problems? } \\
\hline & & \multicolumn{2}{|c|}{$\begin{array}{l}\text { Definitely yes or } \\
\text { Rather yes }\end{array}$} & \multicolumn{2}{|c|}{ Hard to tell } & \multicolumn{2}{|c|}{$\begin{array}{l}\text { Rather not or } \\
\text { definitely not }\end{array}$} & Total \\
\hline & & $\mathrm{n}$ & $\%$ & $\mathrm{n}$ & $\%$ & $\mathrm{n}$ & $\%$ & $\mathrm{n}$ \\
\hline \multirow{4}{*}{$\begin{array}{l}\text { During the } \\
\text { course of your } \\
\text { medical studies, } \\
\text { have you ever } \\
\text { noticed } \\
\text { symptoms in } \\
\text { yourself that } \\
\text { might had } \\
\text { pointed to } \\
\text { depression? }\end{array}$} & $\begin{array}{l}\text { Definitely yes } \\
\text { or Rather yes }\end{array}$ & 388 & $49.43 \%$ & 68 & $60.18 \%$ & 84 & $67.20 \%$ & 540 \\
\hline & Hard to tell & 157 & $20.00 \%$ & 24 & $21.24 \%$ & 15 & $12.00 \%$ & 196 \\
\hline & $\begin{array}{l}\text { Rather not or } \\
\text { definitely not }\end{array}$ & 240 & $30.57 \%$ & 21 & $18.58 \%$ & 26 & $20.80 \%$ & 287 \\
\hline & Total & 785 & $100.00 \%$ & 113 & $100.00 \%$ & 125 & $100.00 \%$ & 1023 \\
\hline
\end{tabular}


Research shows that respondents who claimed that they often felt lonely, the most frequently (69.08\%) had noticed symptoms that might had pointed to depression during the course of their medical studies. Whereas this percentage equaled $47.77 \%$ in case of those who defined as hard to tell whether they often felt lonely. The lowest percentage (33.44\%) was noticed among respondents who didn't often feel lonely. The established differences were very highly statistically significant $\left(\mathrm{Chi}^{2}=133.63 \mathrm{p}=0\right)$. According to analysis, those who participated in social gatherings often enough, the least often $(45.82 \%)$ had noticed symptoms that might had pointed to depression during the course of medical studies. Among respondents for whom it was hard to tell, this percentage had a medium value $(55.39 \%)$. Whereas among those who didn't participate in social gatherings often enough this percentage was the highest $(59.57 \%)$. The established differences were statistically significant $\left(\mathrm{Chi}^{2}=30.25 ; \mathrm{p}=0.0002\right)$. [Table 6.]

Table 6. Link between noticing symptoms that might have pointed to depression during the course of medical studies and frequent feelings of loneliness and feeling that one doesn't participate in social gatherings often enough.

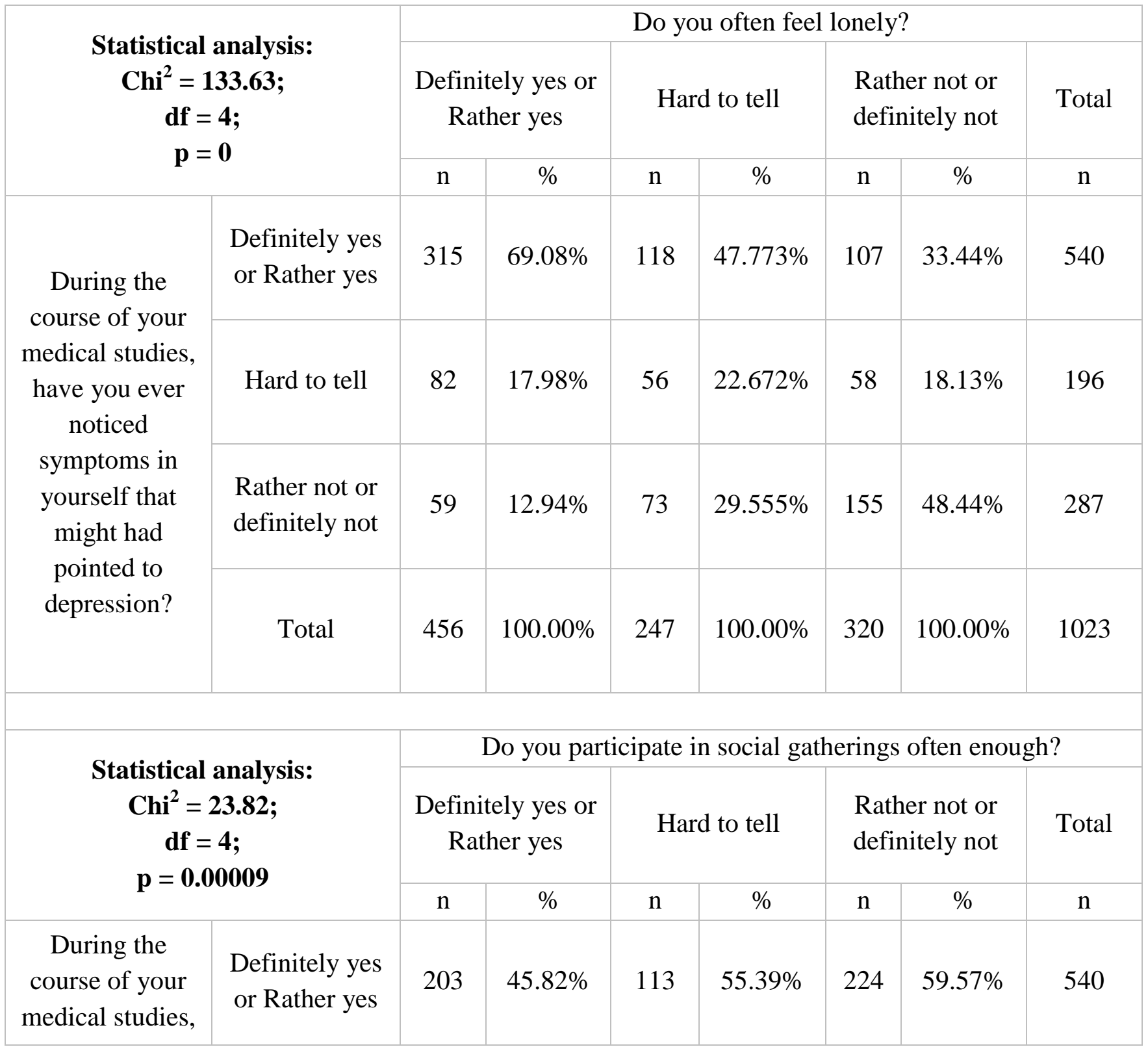




\begin{tabular}{|c|c|c|c|c|c|c|c|c|}
\hline \multirow{3}{*}{$\begin{array}{l}\text { have you ever } \\
\text { noticed } \\
\text { symptoms in } \\
\text { yourself that } \\
\text { might had } \\
\text { pointed to } \\
\text { depression? }\end{array}$} & Hard to tell & 84 & $18.96 \%$ & 37 & $18.14 \%$ & 75 & $19.95 \%$ & 196 \\
\hline & $\begin{array}{l}\text { Rather not or } \\
\text { definitely not }\end{array}$ & 156 & $35.21 \%$ & 54 & $26.47 \%$ & 77 & $20.48 \%$ & 287 \\
\hline & Total & 443 & $100.00 \%$ & 204 & $100.00 \%$ & 376 & $100.00 \%$ & 1023 \\
\hline
\end{tabular}

\section{Discussion}

The research aimed to investigate the occurrence of subjective feeling of depressive symptoms among Polish medical students and to determine predictors of this phenomenon that are related to student's environment. Results of the analysis derived from collected data suggests that as many as $52.79 \%$ of medical students had noticed symptoms that might had pointed to depression during the course of their medical studies.

The research showed a link between noticing symptoms that might had pointed to depression during medical studies and gender. As early as in the 1970s, the difference between two genders in terms of depression was emphasized, pointing that among adults, approximately two times more women than men experience depression in clinical and environmental trials (Weissman i Klerman, 1977) [14].

In a meta-analysis carried out by Puthran et al. the prevalence of depression among female medical students (31.50\%) was higher than among male medical students (24.20\%) [15]. In our research women more often $(54.98 \%)$ than men $(46.00 \%)$ had noticed signs that might had pointed to depression during the course of their medical studies and the difference was close to statistical significance.

The place of residence turned out not to be linked with subjective feeling of depression during the course of medical studies. This result was opposite to the one presented by the Polish Ministry of Health in the "Program of preventing depression in Poland during the years 2016 - 2020", according to which the occurrence of depression among inhabitants of cities is more than two times higher compared to inhabitants of the countryside [16]. Mao Y et al. wrote in their publication that medical students who come from the countryside are more susceptible to depression [17]. Nevertheless it is worth attention that the bigger the hometown, the higher percentage of respondents who had noticed symptoms that might had pointed to depression, seeked professional help. This percentage was the lowest among residents of the countryside, higher among residents of small towns, then among residents of medium cities and the highest among residents of big cities. Whereas the link between living in a family home or outside of family home while studying and subjective feeling of signs that might had suggested depression wasn't noticed. Džubur A et al. obtained different results, according to which medical students who lived with their parents while studying had lower scores of Beck Depression Inventory than those who lived in the dormitories [18]. The research shows a link between noticing signs that might had pointed to depression during the course of medical 
studies and mother's level of education. However, such link wasn't noticed in case of father's level of education. Thao Thi Thu Nguyen et al. whose research also concerned medical students, obtained similar results [9]. However, Surbhi Sidana et al. obtained different results and didn't find a link between symptoms of depression and parent's education [19]. Whereas research carried out by Hui Zhaii et al. points that there exists a link between symptoms of depression and level of education of both parents [20]. According to our research, subjective feeling of symptoms that might had pointed to depression was noticed the most frequently among individuals whose mother had basic, lower secondary or upper secondary education, least frequently - among those whose mother had higher education and the least frequently among those whose mother had basic vocational education. Whereas a link between father's level of education and noticing subjective depressive symptoms during the course of medical studies wasn't found.

Our research didn't find a link between having a parent who is a doctor of medicine or a doctor of dental medicine and subjective feeling of signs of depression during the course of medical studies. Whereas in a research carried out by $S$ Baldassin et al. on a group of 481 medical students it was noticed that not having a doctor parent is a factor which promotes the development of depressive symptoms [21].

Our research shows that relationship with mother is significantly linked to subjective feeling of depression during the course of medical studies among medical students. Similar link was found in case of relationship with father. Research by Kerstis B et al. shows that there exists a link between more secure attachment towards mother or father and lower level of depressive symptoms among youth [22]. According to Thao Thi Thu Nguyen et al. there is a link between occurrence of conflict with parents and feeling of depressive symptoms among medical students [9]. Similar results were obtained by Huang-Chi Lin et al. who investigated the occurrence of depression among youth [23].

Our research shows that good relationship with mother is linked to less frequent feeling of depressive symptoms among medical students. Similarly, smaller risk of feeling of depressive symptoms was associated with good relationship with father. Our research also showed a highly statistically significant link between positive relationship with siblings and less frequent feeling of symptoms that might had pointed to depression during the course of medical studies. Similar results were obtained in a research by L Sun et al., where it was established that there exists a negative correlation between the experience of a family support and occurrence of depressive symptoms among 10140 medical students in a Chinese province Anhui [24].

According to our research, there exists a link between positive relationships with friends and less frequent subjective feeling of depressive symptoms during the course of medical studies. Research by O Coskun et al. showed that respondents who chose social relationships as a source of the biggest happiness during the course of their education, obtained lower results in Beck Depression Scale [25]. Research by R Erschens et al. shows that conflicts with friends are an important source of stress among medical students [26].

Our research shows a link between having a person in whom one can trust in difficult situations and lower prevalence of symptoms that might point to depression. Research by $\mathrm{L}$ Sun et al. shows that support from people from environment is an important component of mental health and subjective feeling of support is significantly linked to less frequent 
occurrence of depressive symptoms [24]. Similar conclusions were made by Y Jeong et al., where it was stated that respondents who perceived their level of interpersonal support as low were at a more than 10 times higher risk of occurrence of depression [27]. In a research concerning Danish medical students by Haldorsen $\mathrm{H}$ et al. showed a link between perception of lack of support from family and friends and more frequent incidence of depressive symptoms [28].

The research also shows that an absence of a person in whom one can trust with all their problems is linked to subjective feeling of depressive symptoms. Similar conclusions were made by Michalska-Leśniewicz according to whom a lack of social support, of for example a close person, might intensify negative self-assessment and thus predestine depression in general population [29].

Our research indicates a link between occurrence of symptoms that might point to depression among medical students during their medical education and often feelings of loneliness.

Students who often felt lonely also more frequently noticed symptoms that might had pointed to depression during the course of medical studies. Research by Matthew $\mathrm{T}$ et al. shows a significant correlation between the presence of depressive symptoms and feelings of loneliness in the population of young adults [30]. Lixia Ge et al. whose research concerned adults at the age of 21 and older, obtained similar results [31]. Similar link was presented in a research by Swami V et al. carried out among medical students. According to their research, there exists a significant link between feelings of loneliness and occurrence of depressive symptoms among students [32].

According to our research, there exists a statistically significant link between participating often enough in social gatherings and lower prevalence of noticing symptoms that might point to depression during the course of medical studies. According to a research by Ball $\mathrm{S}$ and Bax A, lower frequency of participation in social meetings was correlated with higher prevalence of experiencing depressive symptoms among first year medical students in South Korea [33].

\section{Conclusion}

1. The research suggests that predictors of subjective feeling of depression among medical students are: basic, lower secondary or upper secondary mother's level of education, bad or very bad relationship with a parent or not having a parent, bad or very bad relationship with friends or not having any friends, lack of someone that one can count on in a difficult situation, lack of someone in whom one can trust with all their problems, frequent feelings of loneliness, not participating in social gatherings often enough.

2. Depression is a problem that requires more attention from clinical and academic environment. It is important for people from close surroundings of a student to pay attention for symptoms of depression and react in case of noticing such signs by encouraging to have a conversation and to seek professional help. Whereas students should take care of mental hygiene and maintaining contact and improving their relationships with family and friends. 


\section{References}

[1] Rotenstein LS, Ramos MA, Torre M, Segal JB, Peluso MJ, Guille C, Sen S, Mata DA. Prevalence of depression, depressive symptoms, and suicidal ideation among medical students: a systematic review and meta-analysis. JAMA. 2016;316:2214-2236. doi: 10.1001/jama.2016.17324.

[2] Sreeramareddy CT, Shankar PR, Binu VS, Mukhopadhyay C, Ray B, Menezes RG. Psychological morbidity, sources of stress and coping strategies among undergraduate medical students of Nepal. BMC Med Educ. 2007;7:26. PMID: 17678553.

[3] Mukhtar F, Daud S, Manzoor I, Amjad I, Saeed K, Naeem M, Javed M. Bullying of medical students. J Coll Physicians Surg Pak. 2010;20(12):814-818 PMID: 21205548.

[4] Lyndon MP, Strom JM, Alyami HM, Yu TC, Wilson NC, Singh PP, Lemanu DP, Yielder J, Hill AG.. The relationship between academic assessment and psychological distress among medical students: a systematic review. Perspect Med Educ. 2014;3(6):405-418. PMID: 25428333.

[5] Tyssen R, Dolatowski FC, Røvik JO, Thorkildsen RF, Ekeberg O, Hem E, Gude T, Grønvold NT, Vaglum P.. Personality traits and types predict medical school stress: a six-year longitudinal and nationwide study. Med Educ. 2007;41(8):781-787. PMID: 17661886.

[6] Zvauya R, Oyebode F, Day EJ, Thomas CP, Jones LA. A comparison of stress levels, coping styles and psychological morbidity between graduate-entry and traditional undergraduate medical students during the first 2 years at a UK medical school. BMC Res Notes. 2017;10(1):93 PMID: 28193287.

[7] . Moutinho IL, Maddalena NC, Roland RK, Lucchetti AL, Tibiriçá SH, Ezequiel OD, Lucchetti G. Depression, stress and anxiety in medical students: A cross-sectional comparison between students from different semesters. Rev Assoc Med Bras (1992). 2017 Jan 1;63(1):21-28. PMID: 28225885.

[8] Coentre R, Faravelli C, Figueira ML. Assessment of depression and suicidal behaviour among medical students in Portugal. Int J Med Educ. 2016 Oct 29;7:354-363. PMID: 27794561.

[9] Nguyen TTT, Nguyen NTM, Pham MV, Pham HV, Nakamura H. The four-domain structure model of a depression scale for medical students: A cross-sectional study in Haiphong, Vietnam. PLoS One. 2018 Mar 22;13(3):e0194550. PMID: 29566050.

[10] Clark DC, Daugherty SR, Zeldow PB, Gotterer GS, Hedeker D. The relationship between academic performance and severity of depressed mood during medical school. Compr Psychiatry Jul-Aug 1988;29(4):409-20.

[11] Stewart SM, Lam TH, Betson CL, Wong CM, Wong AM. A prospective analysis of stress and academic performance in the first two years of medical school. Med Educ 1999 Apr;33(4):243-50.

[12] Fogleman BY, Vander Zwagg R. Demographic, situational, and scholastic factors in medical school attrition. South Med J. 1981 May;74(5):602-6.

[13] Fahrenkopf AM, Sectish TC, Barger LK, Sharek PJ, Lewin D, Chiang VW, Edwards S, Wiedermann BL, Landrigan CP. Rates of medication errors among depressed and burnt out residents: prospective cohort study. BMJ 2008 Mar 1;336(7642):488-91.

[14]. Weissman MM, Klerman GL. Sex differences and the epidemiology of depression. Arch Gen Psychiatry. 1977 Jan;34(1):98-111. 
[15]. Puthran R, Zhang MW, Tam WW, Ho RC. Prevalence of depression amongst medical students: a meta-analysis. Med Educ. 2016;50(4):456-468. doi: 10.1111/medu.12962.

[16] Polish Ministry of Health- Program for Peventing Depression for years: 2016- 2020. Polish Ministry of Health. 2016; 2018 update. [cited 03.05.2020]. Available from: https://www.gov.pl/web/zdrowie/program-zapobiegania-depresji-w-polsce-na-lata-2016-2020 . Polish.

[17]. Mao Y, Zhang N, Liu J, Zhu B, He R, Wang X. A systematic review of depression and anxiety in medical students in China. BMC Med Educ. 2019;19(1):327. doi: 10.1186/s12909019-1744-2.

[18]. Džubur A, Abdulahović D, Kurspahić-Mujčić A, Džubur A, Loga-Zec S, Škrijelj V. Depressive Symptoms Among Sarajevo University Students: Prevalence and SocioDemographic Correlations.Acta Med Acad. 2018 Nov;47(2):155-164. doi: 10.5644/ama2006124.227.

[19]. Sidana S, Kishore J, Ghosh V, Gulati D, Jiloha R, Anand T. Prevalence of depression in students of a medical college in New Delhi: A cross-sectional study. Australas Med J. 2012;5(5):247-50. doi: 10.4066/AMJ.2012.750. Epub 2012 May 31. PMID: 22848319.

[20]. Zhai H, Chen L, Yang Y, Sun H, Pan H, He J, Zhu X, Sui H, Wang W, Qiu X, Qiao Z, Yang X, Yang J, Yu Y, Ban B, He C. Family and College Environmental Exposures Mediate the Relationship between Parental Education and Depression among College Students. PLoS One. 2016 Mar 18;11(3):e0151759. doi: 10.1371/journal.pone.0151759. eCollection 2016. PMID: 26991783.

[21]. Baldassin S, Alves TC, de Andrade AG, Nogueira Martins LA. The characteristics of depressive symptoms in medical students during medical education and training: a crosssectional study. BMC Med Educ. 2008 Dec 11;8:60.

[22]. Kerstis B, Åslund C, Sonnby K. More secure attachment to the father and the mother is associated with fewer depressive symptoms in adolescents. Ups J Med Sci. 2018 Mar;123(1):62-67. doi: 10.1080/03009734.2018.1439552. Epub 2018 Mar 2. PMID: 29495912.

[23]. Lin HC, Tang TC, Yen JY, Ko CH, Huang CF, Liu SC, Yen CF. Depression and its association with self-esteem, family, peer and school factors in a population of 9586 adolescents in southern Taiwan. Psychiatry Clin Neurosci. 2008 Aug;62(4):412-20. doi: 10.1111/j.1440-1819.2008.01820.x. PMID: 18778438.

[24]. Sun L, Sun LN, Sun YH, Yang LS, Wu HY, Zhang DD, Cao HY, Sun Y. Correlations Between Psychological Symptoms and Social Relationships Among Medical Undergraduates in Anhui Province of China; Int J Psychiatry Med 2011;42(1):29-47.

[25]. Coskun O, Ocalan AO, Ocbe CB, Semiz HO, Budakoglu I. Depression and hopelessness in pre-clinical medical students. Clin Teach. 2019 Aug;16(4):345-351.

[26]. Erschens R, Herrmann-Werner A, Keifenheim KE, Loda T, Bugaj TJ, Nikendei C, LammerdingKöppel M, Zipfel S, Junne F. Differential determination of perceived stress in medical students and high-school graduates due to private and training-related stressors. PLoS One. 2018 Jan 31;13(1):e0191831.

[27]. Jeong Y, Kim JY, Ryu JS, Lee KE, Ha EH, Park H. The Associations between Social Support, Health-Related Behaviors, Socioeconomic Status and Depression in Medical Students. Epidemiol Health. 2010 Nov 24;32:e2010009. 
[28]. Haldorsen H, Bak NH, Dissing A, Petersson B. Stress and symptoms of depression among medical students at the University of Copenhagen. Scand J Public Health. 2014 Feb;42(1):8995.

[29]. Magdalena Michalska-Leśniewicz, Wojciech Gruszczyński. Psychological factors in depression. Psychiatria 2010; 7, 3: 95-103.

[30]. Matthews T, Danese A, Wertz J, Odgers CL, Ambler A, Moffitt TE, Arseneault L. Social isolation, loneliness and depression in young adulthood: a behavioural genetic analysis. Soc Psychiatry Psychiatr Epidemiol. 2016 Mar;51(3):339-48. doi: 10.1007/s00127-016-11787. Epub 2016 Feb 3. PMID: 26843197.

[31]. Ge L, Yap CW, Ong R, Heng BH. Social isolation, loneliness and their relationships with depressive symptoms: A population-based study. PLoS One. 2017 Aug 23;12(8):e0182145. doi: 10.1371/journal.pone.0182145. eCollection 2017. PMID: 28832594. [32]. Swami V, Chamorro-Premuzic T, Sinniah D, Maniam T, Kannan K, Stanistreet D, Furnham A. General health mediates the relationship between loneliness, life satisfaction and depression. A study with Malaysian medical students. Soc Psychiatry Psychiatr Epidemiol. 2007 Feb;42(2):161-6. Epub 2006 Dec 18. PMID: 17180631.

[33]. Ball S, Bax A, Self-care in Medical Education: Effectiveness of Health-Habits Interventions for First-Year Medical Students. Acad Med. 2002 Sep;77(9):911-7. 